\title{
LA CIENCIA: UN CAMINO HACIA DIOS PARA ARTURO ALDUNATE PHILLIPS Ciro E. Schmidt Andrade*
}

\author{
SCIENCE: THE PATH TO GOD ACCORDING \\ to ARTHUR AldunAte PHILLIPS
}

Resumen: Arturo Aldunate, Premio Nacional de Literatura, se interesó por la ciencia, la literatura, la filosofía y la religión. En este trabajo se aborda su reflexión sobre temas relacionados con el conocimiento, especialmente en torno a las relaciones entre ciencias, metafísica y religión.

PALABRAS CLAVE: experiencia, ciencias, metafísica, Dios.
ABSTRACT: Arturo Aldunate Phillips, National Prize Winner in Literature studied science, literature, philosophy, and religion. In this article, we address his views on topics associated with knowledge, namely the relationship between science, metaphysics, and religion.

KEYWORDS: experience, sciences, metaphysics, God.

* Universidad Católica de Santiago, sede Puerto Montt. 


\section{LA CIENCIA: UN CAMINO HACIA DIOS PARA ARTURO ALDUNATE PHILLIPS*}

Todos mis libros son, en realidad, uno solo, continuación uno del otro

Arturo Aldunate Phillips, como escritor multifacético, se ocupó de diversas ramas del saber, sobre todo el de las ciencias y en especial la física y la astronomía. Él mismo decía: "Vivo en un mundo en los

* Arturo Aldunate Phillips fue un hombre versátil: ingeniero, estudioso de la ciencia, ensayista, poeta, profesor, deportista, un conocedor de varios idiomas; en resumen, un gran investigador de todas las disciplinas del saber. Quienes conocieron a este intelectual, nacido el 9 de febrero de 1902 en Santiago, destacaron su inmenso interés por las ciencias, las matemáticas y también la literatura. En 1976 le fue otorgado el Premio Nacional de Literatura, en atención a una vida consagrada a la literatura y especialmente a la divulgación científica, cualidad que le permitió constituirse en creador de un género nuevo en Chile: el ensayo científico. Falleció en 1985. Para las citas de este texto se han utilizado las siguientes abreviaturas: Quinta Dimensión (QD), Santiago de Chile, Edit. Universitaria, 1958; Una flecha en el aire y otros ensayos (FA), Santiago de Chile, Zig-Zag, 1966; Los robots no tienen a Dios en el corazón (RD), Santiago de Chile, Andrés Bello, 1963; Los caballos azules (CA), Valparaíso, Ediciones Universitarias de aledaños de la ciencia"1 y creo que habría que agregar: aledaño a la filosofía. Su abundante información es a veces sobrepasada por nuevos descubrimientos, pero la problemática que plantea sigue siempre presente. Autor hoy poco frecuentado, al que solo se encuentra en listas de premios nacionales y cuyas obras son difíciles de encontrar. En este trabajo se presentan aspectos de su visión del hombre, pues fue un profundo humanista, así como algunas de las dificultades que plantean en el mundo de las ciencias los problemas del conocimiento.

Valparaíso, 1977; A horcajadas en la luz (HL), Santiago de Chile, Zig-Zag, 3a. ed., 1969; Luz, sombra de Dios (LD), Santiago de Chile, Editorial Universitaria, 2a. ed., 1983; Hombres, máquinas y estrellas (HE), Santiago de Chile, Editorial Universitaria, 1972. ${ }^{1}$ HE 9. 


\section{El ser del hombre}

La vida impulsa la creación de moléculas primero y células de extraordinaria complejidad después, y estas se van haciendo más complicadas, mientras más perfectos son los organismos vivos en la evolución. Es decir, sobre la ley entrópica de que la energía tiende a la desorganización, ha aparecido, sin dejar de cumplir, en su aspecto estrictamente material, con las otras leyes físicas, una nueva evolución: la evolución de los seres vivos que se orienta tras un permanente aumento de la complejidad y el perfeccionamiento de sus organizaciones y que camina impulsada por un deseo instintivo de supervivencia, por una teleología todavía desconocida.

Sin embargo - indicaAldunatela especie humana que, al igual que los demás seres vivos, contradice en su propio organismo la ley de la entropía por el solo hecho de existir, al crear dispositivos mecánicos que constituyen también una reorganización de la materia y la energía se opone cada día en mayor escala y con mayor frecuencia a la tendencia cósmica a la muerte. El hombre utiliza la inteligencia que ha logrado obtener en esta prodigiosa evolución teleológica en su propio perfeccionamiento y es lo que le corresponde hacer. ${ }^{2}$

\footnotetext{
${ }^{2} \mathrm{RD} 38,42,55$.
}

La vida reorganiza la materia y la energía. Vuelve atrás y crea nuevas y complejas disimetrías, y para realizar su propósito, busca las soluciones que las leyes físicas y matemáticas señalan como menos probables, aunque no imposibles; lo hace de tal manera que la vida ha sido considerada por algunos hombres de ciencia como una antiprobabilidad. Igualmente, en el ser vivo el "algo más" proviene de su razón de ser, de los desconocidos objetivos tras los cuales no solo acciona él mismo, sino también su especie, que modifica continuamente sus ejemplares impulsada por una tendencia a evolucionar progresando por la fuerza de una acción antientrópica y, por consiguiente, por la búsqueda de objetivos o metas muy improbables.

El organismo vivo no puede considerarse como la simple suma de sus partes. Las condiciones necesarias y suficientes para que un objeto sea reconocido como un organismo vivo son que debe ser un conjunto de materia distinto o separado, con un límite preciso y bien definido; debe experimentar intercambios permanentes de materia con su ambiente o alrededores, sin alteración manifiesta de sus propiedades dentro de un corto periodo, y debe haber tenido su origen en un proceso de división y fraccionamiento de uno o dos objetos de la misma clase. 
Aquí está la razón por la cual las acciones humanas y algunas de los animales no parecen estúpidas: están autoreguladas y no predeterminadas; es la propia acción la que se regula. Se puede corregir durante su proceso o aun se detiene. Hay un abismo entre los dos procedimientos. Entre el tosco martillo elemental formado por una piedra asida por los todavía torpes dedos del hombre de Cromañón y los mil dispositivos electrónicos de precisión accionados por un astronauta instalado en un satélite artificial hay un largo camino recorrido. ${ }^{3}$

El hombre ha construido máquinas, se lo haya propuesto o no, a su imagen y semejanza, pues con ellas pretende reemplazar trabajos que antes efectuaba él mismo. Es indudable que sin el hombre la máquina no podría existir y que, aun desaparecido su creador, cumpliría mientras funcione una técnica o una tarea que se le enseñó y más allá de la cual no podrá ir por propia resolución. El hombre, si tuviera que actuar en lugar de la máquina, no mostraría una conducta predeterminada, sino que actuaría y controlaría su actuación de acuerdo con sus resultados: corrige su acción para cumplir el fin deseado. La conducta de las máquinas está lejos de corresponder a lo que se llama "finalismo", pues no cambian su conducta según las contingencias. El hombre crea la máquina con un fin utilitario: ya sea para ganar dinero que le permita gozar de ciertas formas de vida, ya para evitarse trabajo o perfeccionar lo que sus manos pueden realizar, ya para tener más elementos que lo ayudan a vivir mejor, ya para tener el goce espiritual de crear o hacer el bien. Las máquinas no poseen la plasticidad casi ilimitada del hombre y necesitan un artífice, alguien que las conciba y las "proyecte". Antes de ser realidad, antes de ser siquiera teoría, requieren una inteligencia que imagine su estructura y su forma y sus características de funcionamiento. Creadas por el hombre, están a su servicio. Una diferencia importante es la libertad, y con ello, la autonomía y la independencia. ${ }^{4}$

Es indispensable insistir en que, si bien según la segunda ley de la termodinámica la naturaleza posee una tendencia a la desorganización, esto sucede dentro de sistemas aislados que no reciben, por consiguiente, materia o energía de otros sistemas. Nosotros, en nuestra calidad de seres humanos, no somos un sistema aislado. Tomamos del exterior alimentos que generan energía y somos, por lo tanto, partes de un mundo mucho más amplio que contiene esas fuentes de vida. Como señal de nuestra integración a ese mundo más vasto 
resulta demostrativo el hecho de que de él recibimos, a través de nuestros sentidos, permanente información. ${ }^{5}$

Toda la investigación científica, todas las búsquedas realizadas dentro del irisado enjambre del pensamiento, obedecen a la profunda necesidad del hombre de encontrarse a sí mismo. Y surgen, reiteradamente, las tan manidas, pero no por ello menos actuales, preguntas: ¿De dónde venimos? ¿Qué somos? ¿Adónde vamos?

Las incursiones por las profundidades del tiempo y del espacio, los sondeos cosmológicos, las penetraciones en las intimidades recónditas de la materia, traen noticias que rondan en torno a estas interrogaciones. Pero las respuestas son insuficientes; nos cuentan del devenir cósmico desde una lejanísima etapa, pero no logran vislumbrar ni la más somera información de la génesis y razón de ser del Universo, cuya esencia permanece tan hermética y tercamente escondida como siempre. Si bien nos muestran nuevos y hasta ayer desconocidos aspectos de la Creación, al ampliar los conocimientos humanos, al dilatar el horizonte del mundo comprensible, aumentan también la extensión y vastedad de lo desconocido. Y si insistimos en internarnos por esos intrincados caminos, nos encontraremos en el enrarecido contorno que rodea a la ciencia en sus extra-

${ }^{5}$ HL 267. muros y al cual, a falta de un nombre más sabio, llamamos metafísica.

Cuando miramos hacia el Principio debemos raciocinar con humildad y con la misma lógica utilizada al caminar desde los lejanos ayeres hacia el filo del hoy. En esta forma podemos concluir algo bien alentador: la ciencia ha logrado notables avances en lo que Albert Einstein llamó "la ordenación lógica de nuestras caóticas experiencias sensoriales". A la sazón, resulta de toda evidencia: el Universo no es un caos y su comportamiento obedece a leyes y sistemas, ritmos y funciones intrínsecamente matemáticos, orientados por una finalidad teleológica cuya meta no conocemos, pero - señala Aldunate - será alcanzable.

La aparición de la inteligencia constituye un poderoso aliado de la vida; su creadora capacidad ha tratado de protegerla modificando el medio ambiente y eliminando los factores hostiles. ${ }^{6}$ Nuestra finalidad es bien clara: insistir en la insignificancia espacial y temporal del hombre y su ninguna influencia ni intervención en la estructura o el devenir de los evos universales distantes, ni en el presente devenir cuya existencia pretenden darnos a conocer nuestros modestos sentidos. Y junto con mostrarle su incapacidad e insignificancia, destacar la asombrosa paradoja: su posesión de dones de origen divino. En

$$
{ }^{6} \text { HL } 263 \text { y } 269 .
$$


efecto, esa diminuta partícula viva de polvo cósmico, además de recibir del Creador múltiples dádivas, ha sido dotada del Don de saber que existe y que cada una es única, diferente de todas las nacidas y por nacer. Y el Omnisciente Creador conoce a cada uno de estos corpúsculos vivos a quienes generosamente les otorga el incomprensible rango de hijos suyos.

Entre las incontables dádivas recibidas, que menciona con insistencia Aldunate, cabe recordar las tres que dan más claro testimonio de la calidad de hijos de Él.

Primer Don: la inteligencia, la cual nos da los medios para imaginar, pensar y crear no solo ideas, sino realidades tangibles.

Segundo Don: la capacidad de amar. Además de una límpida alegría, este Don lleva en germen el posible ejercicio de las virtudes del Espíritu. A su influjo nace la familia, con todos los atributos para constituir la célula fundamental de una sociedad digna de ser poseedora de la luz del pensamiento. De tales fuentes deben brotar, bajo los signos del amor, la paz, la justicia, la generosidad, la bondad, la lealtad, la caridad y todas las virtudes del espíritu. Y solo en tal marco de armonía y belleza podrá el hombre vivir momentos de íntima e inefable felicidad.

Tercer Don: el libre albedrío. Este insólito tercer don coloca al hombre ante un camino de luz y sombra ante una permanente alternativa: decidir la condición y objetivos de sus actos; le dio la desconcertante libertad para contradecir o ignorar las disposiciones o conductas que deberían ser cumplidas para la normal convivencia entre los seres inteligentes y hermanos y la capacidad para quebrar las leyes reguladoras del transcurrir universal. En nuestros días comprobamos, con asombrado y penoso temor, cómo destruye su morada celeste y, perdida la razón, derrama sin aprensión sangre de sus hermanos. Que el sacrificio y la caridad tienen su compensación en el grado que proporciona el realizarlos es un argumento más para separar al hombre de la máquina y del irracional, porque estos no podrán nunca tener tal tipo de satisfacción, que es eminentemente espiritual; ellos no se verán nunca impulsados por ese acicate que tantos actos extraordinarios ha producido sobre la tierra. ${ }^{7}$

\section{Estatuto epistemológico}

El conocer del hombre parte de la admiración. Aldunate se acerca en ello y en sus procesos de conformación del conocimiento a Aristóteles y Santo Tomás. La eterna curiosidad del hombre por saber quién es, de dónde viene $\mathrm{y}$ adónde camina puede encontrar en

\footnotetext{
${ }^{7}$ LD 332-333; RD 181.
} 
este contacto de nueva índole con el cosmos alucinantes respuestas. $\mathrm{Su}$ curiosidad está aguijoneada por un deseo de descubrir una imagen comprensible del Universo. Solo así podrá satisfacer su secreta esperanza de averiguar algún día qué es y hacia dónde camina. Cualquier fantasía referente al mundo en que vivimos lo atrae apasionadamente, a pesar de que el tiempo parece ser una limitación en su capacidad de conocer. ${ }^{8}$

Las atribuciones de un método están delimitadas por la índole de la realidad a cuyo conocimiento ha de aplicarse. La ciencia cuenta con un conocimiento precientífico de aquello que se propone investigar. Este conocimiento es inadecuado y defectivo, precisamente desde el punto de vista del método. Al referirnos a la capacidad humana de mirar, o sea, de saber que se ve, en cuyo "saber" surge el misterio del conocimiento, muchas veces nos percatamos de personas que, si bien es cierto, han visto, nada han mirado, porque el fenómeno intelectual del conocimiento no se ha producido. ${ }^{9}$

A partir de la pregunta sobre la verdad del conocimiento, hubo de surgir el interrogante: el mundo que creemos conocer ¿tiene, intrínsecamente, las características que le atribuimos o estas constituyen solo una

${ }^{8} \mathrm{HE}$ 44; CA 283; LD 176.

${ }^{9}$ LD 93. concepción humana? La imagen que nos hemos formado de la realidad, ¿es cierta y absoluta o resulta de un condicionado y accidental punto de vista? ¿No se tratará de consecuencias de determinadas posiciones del observador, de peculiares interpretaciones de fenómenos físicos conocidos solo fragmentariamente? ¿Hasta dónde son "verdaderos" los conceptos elaborados por la mente sobre el Universo? ¿Serán permanentes o circunstanciales las imágenes que hemos concebido de su apariencia y de nosotros mismos? El 'cero' término y final, y aun el 'cero puro o absoluto', como lo que termina definitivamente; la 'unicidad', o carencia de partes; el tiempo detenido, que no transcurre, $\mathrm{y}$ otras inmateriales formulaciones que lindan con la metafísica, productos del modo humano de reflexionar o de especular y, por ende, atenidos a nuestra natural suerte de concebir la realidad formada por tiempo y espacio, ¿representan solo un artificial esfuerzo del intelecto por encasillar fenómenos ajenos a su presente capacidad de comprensión? ${ }^{10}$

Para obtener respuestas a tales cuestiones y a otras semejantes, es necesario realizar un examen detenido, pues una tromba de acontecimientos nos arrastra. Crece la avidez por lo nuevo y el vibrante y acrecido aluvión del saber altera profunda-

\footnotetext{
${ }^{10} \mathrm{CA} 427$.
} 
mente las proporciones cósmicas del hombre; ha mudado su actitud ante la Vida. La noción de lo objetivo, reservada al mundo de la física, en contraposición con lo subjetivo, situado fuera de sus ámbitos, no puede sostenerse ya tan enfáticamente. Nuestra imagen del Universo, nuestro conocimiento de la realidad, nacen de una interpretación realizada a través de un proceso desconocido.

Desde luego, el estudio del Universo estelar del cual formamos parte $\mathrm{y}$ de leyes físicas que rigen su conducta dará bases insospechadas para obtener nuevos conocimientos y para comprobar los actuales. El progreso tecnológico que hoy nos asombra; el avance en los medios de comunicación y transporte causantes de un cambio fundamental en la vida humana; la victoriosa lucha contra tantos males que castigaban al hombre, fueron consecuencia de todos aquellos ajetreos, audacias, investigaciones y geniales planteamientos. ${ }^{11} \mathrm{La}$ asombrosa fuerza de penetración y avance de la ciencia moderna y la eficacia de la tecnología científica ejercitadas, primero, desde nuestro propio planeta y, más tarde, desde artilugios mecánicos y electrónicos internados en lejanías abismales, han ido comprobando la prevaleciente validez universal de las leyes físicas descubiertas en la Tierra y sus contornos, y la

\footnotetext{
${ }^{11} \mathrm{CA} 365$.
}

presencia por doquier de la misma materia prima de la propia estructura somática del hombre y de la morada cósmica que lo alberga. Pero una cosa es cierta: las expresiones que deben usar los hombres de ciencia y los matemáticos para designar determinados valores o elementos son, por un lado, producto de la limitación del lenguaje y, por otro, del deseo innato del hombre de objetivar todo lo que conoce. La huella del orden en el caos de la información, la huella matemática de este orden nos impulsa a ir más allá.

\section{Los sentidos}

La imagen física del ambiente que nos rodea y del cosmos penetrado por la ciencia se ha configurado a través de informaciones o mensajes emitidos por la materia o la energía existente en esos ámbitos. Esas informaciones, bajo la forma de ondas o vibraciones, inciden en nuestros órganos sensoriales, los cuales retransmiten sus impactos al cerebro por medio del sistema nervioso. El órgano central del complejo neurológico elabora entonces una imagen y toma conciencia de ella. Desgraciadamente esas informaciones son precarias y caóticas y las “imágenes" obtenidas solo son interpretaciones de la realidad externa. 
Las informaciones son precarias por cuanto los sentidos captan solo una parte reducida del espectro electromagnético y de las ondas mecánicas. La inteligencia ha logrado construir receptores artificiales para transformar algunas de estas vibraciones en otras que son accesibles; pero son recibidas con imperfecciones o alteraciones propias de los instrumentos captores, los cuales, además, realizan una suerte de traducción del fenómeno externo, seguramente también deformadora. Pero nuestro conocimiento, además de precario, era caótico. Ello porque los mensajes recibidos lo son en forma irregular, desordenada e incompleta. Afortunadamente, la creciente capacidad de raciocinio de nuestros científicos y pensadores advirtió las deformaciones o arbitrariedades de tales observaciones. ${ }^{12}$

Las informativas ondas energéticas y mecánicas alcanzan al hombre a raudales, y lo hacen en un increíble desorden. Ello explica la caótica diversidad de nuestras experiencias sensoriales. Los conceptos que poseemos de la naturaleza, de la vida y del Universo nos han llegado transmitidos por este sistema de ondas y vibraciones a través de los sentidos de la vista, el oído, el tacto, el gusto, el olfato y otros menos definidos, y que han sido interpretados por la inteli-

\footnotetext{
${ }^{12}$ HE 122 y 124.
}

gencia y arbitrariamente catalogados. Aun cuando podamos aumentar la zona de percepción del ser humano, es indudable que, de toda la compleja y vasta maraña de vibraciones que nos proyecta la existencia del mundo externo, los sentidos solo percibirán una pequeñísima fracción, y es solo ella la que genera nuestro conocimiento.

Para que se comprenda mejor esta limitada zona de percepción del hombre, Aldunate analiza dos aspectos del problema planteado: primero, la extensa gama de ondas o vibraciones que hemos logrado saber que se propagan a través del espacio y de los elementos que en él se albergan $y$, en seguida, la limitada capacidad y alcance de los sentidos humanos para percibirlas. La imagen que poseemos del Universo está formada dentro de nosotros mismos, subordinada, primero, a la sensibilidad de nuestros medios de percepción y después, a la interpretación que de los impactos recibidos elabora nuestro cerebro. Hay que convenir en que la imagen o el concepto que tenemos de la realidad son eminentemente humanos, productos, en último término, de una interpretación de nuestros sentidos y de nuestro cerebro y, por tanto, de naturaleza indiscutiblemente subjetiva. Esto, si lo profundizamos, nos lleva a la conclusión de que el mundo "objetivo" que observamos está en gran medida 
dentro de nosotros mismos, y lo inestable y subjetivo que es el concepto que tenemos, científicamente hablando, del mundo en que vivimos. ${ }^{13}$

El hombre, para conocer la realidad que lo circunda, o sea, para percibir este continuo flujo de informaciones, mensajes o recados que vienen de todo el Orbe, posee unos captores de las ondas que los transportan: son sus sentidos. Pero dado el perfeccionamiento de la tecnología que creó, estos no solo se limitan ya a lo natural del ser humano, sino que están complementados por elementos o accesorios que perfeccionan o dan mayor eficacia a aquellos o por sentidos auténticamente artificiales. Para mejorar la eficiencia de los sentidos originales, solamente en los anteojos de larga vista, en los telescopios, en los microscopios, en los audífonos y otros artilugios destinados a amplificar las informaciones de los receptores naturales. ${ }^{14}$ Fácil es comprender, entonces, que las ideas y las imágenes que el hombre tiene de la realidad cósmica son meramente subjetivas y humanas. Como lo han expresado destacados científicos, el hombre no tiene conocimiento de la realidad absoluta.

En resumen, todo el conocimiento que poseemos del mundo material

${ }^{13}$ QD 67, 95, 69, 74, 79.

${ }^{14}$ LD 92 . del que formamos parte proviene de informaciones captadas por nuestros sentidos y que el sistema neurológico transmite al cerebro. Esta central del conocimiento interpreta el mensaje y concibe o configura una imagen. Sin embargo, el fenómeno es bastante más impreciso, pues los receptores biológicos, nuestros sentidos, seleccionan según su capacidad y sensibilidad parte de la información recibida, y el sistema nervioso, a su vez, al transmitir las señales, las interpreta y de todos modos las altera o deteriora como resultado de una suerte de entropía producida durante la transmisión y que disminuye pero nunca aumenta la información. La eficacia y la exactitud con que el mensaje que configura el cerebro es el producto de una interpretación humana subjetiva.

\section{Mundo de las ciencias}

Si subjetivas eran las imágenes del mundo que por su esencia interpretativa creaba nuestra conciencia, con mayor razón se harán desobjetivizadas cuando deban concretarse y se expresen a través de relaciones numéricas, siendo que los números son una de las realidades cósmicas, descubiertas por la aguda condición investigadora de la inteligencia del hombre. 
La ciencia es una tentativa de hacer que la caótica diversidad de nuestras experiencias sensoriales corresponda a un sistema de "pensamiento lógicamente ordenado". Orientadora definición; pasa sobre lo circunstancial para proyectarse en el ámbito del conocimiento y del modo de adquirirlo.

Es perfectamente posible que ciertas leyes naturales que el físico establece como resultado de sus experiencias objetivas no sean leyes de la naturaleza, sino que procedan de él mismo, por estar condicionadas a las limitaciones de sus instrumentos, a su personal modo de observar y a la interpretación de su pensamiento. ${ }^{15}$ Desde Planck la física no puede sostener que ocurrirá con seguridad tal o cual cosa, sino solo que existe una probabilidad de que esto o aquello tenga lugar. La teoría de los quantos únicamente sostiene que la naturaleza se nos presenta "como si" en su acaecer estuviera incluido lo contingente.

Si ampliamos estos planteamientos y los profundizamos, llegaremos a una clara conclusión: el mundo llamado objetivo reside, en gran manera, dentro de nosotros mismos. Nuestras verdades o realidades no son, pues, absolutas y no pueden ser comprobadas en definitiva, pues para ello deberían utilizarse los mismos insuficientes y deformadores elementos y proce-

\footnotetext{
${ }^{15}$ QD 78, 91, 94; HL 93 y 105.
}

sos que les dieron vida. Sin embargo tiene un anclaje. La estructura conceptual del hombre de hoy posee una solidez que impide considerarla como parte de un mundo irreal marchando a la deriva, sujeto a ímpetus desconocidos que podrían llevamos a un estéril escepticismo. Lo sorprendente y demostrativo de la orientación verdadera de la ciencia es la claridad con que ella misma valoriza sus avances o les da su auténtica condición. La relatividad de Einstein, la ley de incertidumbre de Heisenberg, la evasión de la causalidad y del determinismo provocada por la mecánica quántica son claras demostraciones de que la ciencia sabe cómo son de interpretativas sus afirmaciones, cómo son el resultado de una determinada posición intelectual de verdaderas y justas relaciones.

Los números naturales, en efecto, y las constantes universales son como el anclaje de la urdimbre que sostiene la realidad, esta realidad relativa y cambiante, producto de una interpretación humana de las manifestaciones del cosmos. Son valores absolutos que aparecen siempre inmutables, cualesquiera que sean las condiciones teóricas u objetivas en las cuales se les ve aparecer, y muestran que todo el edificio conceptual creado por la inteligencia humana, a pesar de su subjetividad, está férreamente coordinado y amarrado a fundamentos 
ajenos a toda interpretación. Durante siglos hombres de genio descubrieron y pusieron en evidencia aspectos de este sistema matemático que empezaba a aflorar en muchos campos: la música, la arquitectura, el mundo de los animales y las plantas, el cielo de las estrellas y el concierto de las ondas de luz y de la energía electromagnética. Llegados a nuestros días y habiéndose aumentado los dominios del saber humano, han aparecido por doquier la ordenación, el sistema, el sometimiento a cadencias y relaciones de todo lo que acontece. Y ello está demostrando que la realidad cósmica se configura sobre una trama que, a primera vista y según sea la escala de la observación, no se advierte, pero que resulta finalmente amarrada a los números $\mathrm{y}$, por ende, indiscutiblemente rítmica y matemática. ${ }^{16} \mathrm{E} 1$ hombre ha aumentado y perfeccionado su capacidad para elaborar cada día más y más complejos artículos. Empezaron a levantarse las nuevas y para muchos inquietantes estructuras de los llamados mecanismos inteligentes. Aparecieron artificios capaces no solo de agregar fuerza muscular, fuerza mecánica y material o eficacia a la labor del hombre, sino también capaces de ayudarlo en sus tareas intelectuales. La verdad es que ha empezado una era en que el hombre puede, con el uso de ingeniosas crea-

\footnotetext{
${ }^{16}$ QD $111 ; 135$ FA 14.
}

ciones suyas, aumentar la eficacia de su cerebro, acelerar la resolución de sus problemas matemáticos $\mathrm{y}$ técnicos, memorizar millones de datos y antecedentes, y ordenarlos con la necesaria secuencia y en la debida oportunidad para el desarrollo de sus más ambiciosas concepciones. Sin embargo, lo fundamental es el uso en aparatos o instrumentos creados por el hombre de sistemas o normas semejantes a los utilizados por los seres vivos y por los seres vivos inteligentes. Es aquí donde brilla el momento estelar, donde enfrentamos la etapa crucial.

Empero, esa formulación de relaciones, esa postulación de leyes, requiere un lenguaje que no esté sujeto a la interpretación de quien las examina. Entonces, la física echa mano del único modo de expresión riguroso de que dispone y el único sistema de representaciones exactas, y así, las matemáticas, con sus herramientas algebraicas y geométricas, pasan a constituir una exigencia para que pueda considerarse que una ley está científicamente expresada. ¿Qué nuevo alcance tiene esta exigencia? ¿Qué característica inevitable se agrega ahora a la ciencia, tan hondamente metida en la filosofía y en la actitud vital del hombre?

Sería ilusorio buscar en los sistemas y métodos de la biología de hoy alguna relación con las normas o con 
las bases de la geometría, semejante a la que advertimos en los planteamientos teóricos de la física o, menos ostensiblemente, de la química. Sin embargo, la poéticamente llamada "nostalgia geométrica" de los hombres de ciencia y de los investigadores de la física, la química y otras ciencias, se advierte también en los biólogos, que buscan desembozadamente la posibilidad de introducir en sus planteamientos o en sus métodos de generalización analogías geométricas; por ejemplo, en la búsqueda de las leyes de la herencia a través de las normas $\mathrm{u}$ ordenaciones permanentes a que estarían sometidas la transformación del núcleo y la división del contenido proteínico. Pero esta sabiduría matemática o geométrica de las formas relacionadas con la vida tiene otro significado y otra tarea, no limitada ya solo a crear belleza, sino a cumplir necesidades vitales. Desde luego, podemos preguntarnos por qué las plantas, los cuernos de los animales, la musculatura, el caparazón de los caracoles, las formas de las flores, utilizan la espiral logarítmica de la proporción áurea. ¿Es solo por una innata orientación hacia la belleza? ${ }^{17}$

La ciencia ha debido asombrarse cada día al comprobar que el comportamiento del mundo físico y su estructura obedecen a un sistema perfectamente establecido y con- gruente; es más, obedecen a un sistema matemático riguroso. Existe una inteligente ordenación del mundo de la materia. Se da una correlación entre belleza y matemáticas que es una de las características más asombrosas del mundo en que vivimos. Aldunate presenta algunos ejemplos que pueden justificar las bases sobre las cuales afirma que, teóricamente, al hombre le es dado alcanzar la belleza por el camino de la intuición artística, aun lleno de luces y de sombras, o a través del pensamiento matemático, impedido por sus limitaciones de conocer y formular las ecuaciones de belleza que escribieron los dedos luminosos de Dios. ${ }^{18}$ Señala cierta relación de la belleza con los seres vivos, y explorando algunos campos de la morfología biológica, empieza a descubrir curiosas relaciones con las matemáticas y, lo que es tan asombroso, estas relaciones también conciernen a las condiciones de belleza.

Tras su afán de verdad, y conscientes de la limitada condición humana de esa verdad, los científicos agudizan sin descanso sus instrumentos y sus inteligencias con la intención de descubrir los ritmos, los sistemas, las relaciones, la trama matemática a que se atienen los fenómenos universales y tratan de que correspondan a un pensamiento lógicamente ordenado. No obstante, la metafísica,

${ }^{17}$ FA 24 y 28.

${ }^{18}$ RD 33; FA 18. 
ubicada más allá de la física y en el ámbito del pensamiento abstracto, $\mathrm{y}$ la ciencia experimental, se acercan y hacen cada vez más imprecisas sus fronteras. Para agravar el problema, las matemáticas se muestran progresivamente más capaces de expresar ciertas características subjetivas, advertidas por el hombre en su apreciación de la naturaleza, y reconocen su enclavamiento en conceptos de orden todavía desconocido e impreciso. Todo hombre culto sabe que las matemáticas, lenguaje riguroso y sin matices, han desarrollado estructuras geométricas y algebraicas 1lamadas "de ordenación", pero pocos están informados de cómo la gran ciencia ha concebido formaciones que permiten dar formulación abstracta a conceptos intuitivos, tales como los de límite, continuidad u otros, todos productos de nuestra concepción subjetiva del espacio. ${ }^{19}$ Hoy han aparecido por doquier la ordenación, el sistema, el sometimiento a cadencias y relaciones de todo lo que acontece. Y ello está demostrando, a juicio de Aldunate, que la realidad cósmica se configura sobre una trama que, a primera vista y según sea la escala de la observación, no se advierte, pero que resulta finalmente vinculada a los números, $\mathrm{y}$, por ende, indiscutiblemente rítmica y matemática.

${ }^{19}$ HE 14-16.
Así, la belleza resulta de un equilibrio, de una armonía, de una euritmia de valores. La belleza aparece como el trasunto de la apropiada combinación de distancias y, por consiguiente, de formas; de la combinación de colores y sonidos (a la postre solo vibraciones u ondas), movimientos estrictamente definidos por determinados números. Para desconcertarnos, aflora también como belleza la combinación de actitudes o sensaciones cuya extensión o secuencia cuantitativa escapa todavía a las actuales capacidades de la ciencia y del conocimiento. Las formas clásicas de belleza (Partenón, Capilla Sixtina, Bach) obedecen a ritmos y funciones susceptibles de ser expresadas por ecuaciones matemáticas y parecen guardar, entre sus elementos constitutivos, relaciones y proporciones formales constantes, mantenidas bajo la insobornable tutela de los números. Ello se manifiesta de igual forma en la naturaleza, por ejemplo, en la espiral foliácea. Esta espiral tiene dos tendencias, una a ascender y la otra a girar alrededor del tallo, y regula muchas de las disposiciones que embellecen las flores. Todos estos maravillosos dibujos de la naturaleza están sujetos estrictamente a esta espiral logarítmica.

Arriba nos preguntábamos por qué las plantas, los cuernos de los animales, la musculatura, el caparazón 
de los caracoles, las formas de las flores utilizan la espiral logarítmica de la proporción áurea. La respuesta es, a juicio de Aldunate, asombrosa. Esta innata orientación hacia lo que estimamos bello es posible a través de relaciones que resultan ser además las necesarias y más convenientes para el crecimiento y desarrollo del ente vivo que las emplea. Esta curva es la única que permite al animal o a la planta crecer por la adición de elementos siempre semejantes. Los matemáticos han probado que las espirales logarítmicas son las únicas curvas que tienen esta propiedad. Por lo mismo expone múltiples ejemplos y señala además lo largo que sería numerar los encuentros, cada día más abundantes de relaciones matemáticas en los fenómenos físicos, químicos, astronómicos, biológicos y de todo orden realizados por la ciencia en el último siglo. El ritmo, la ordenación, el sistema "numéricamente matizado" se hace presente por todas partes como una trama, una urdimbre, sobre la cual se tejen o se bordan los fenómenos universales. ${ }^{20}$

\section{Hacia la metafísica}

Si bien todas las ramas del saber y especialmente las relacionadas con la física y las matemáticas ven dilatar- se sus dominios y su tesoro de conocimientos, ven también crecer, en escala inmensamente superior, los ámbitos de lo desconocido. Ante un cambio tan trascendental de la imagen del Universo, la ciencia ha debido reconocer las zonas en que le es permitido actuar; constreñido el análisis objetivo a detenerse en el umbral del ego individual, porque más allá de él sus medios de observación no responden. Descubierta en todos los procesos y en todas las creaciones la huella inconfundible de una inteligencia superior, la actitud filosófica del hombre ha debido, también, sufrir una alteración fundamental. Han quedado hoy abiertos, sin menoscabo para la Ciencia, todos los miradores que dan al campo del espíritu: el sentimiento, la intuición, la fe, el amor, la belleza y, en general, los valores anímicos que no pueden ser encuadrados en las ecuaciones científicas. ${ }^{21}$ Las paradójicas o contradictorias constataciones establecidas por los hombres de ciencia son una prueba más del misterio de nuestro mundo y de lo mucho que aún nos queda por descubrir.

Las fuentes y los dominios de las fuerzas espirituales, si bien no llegan a nuestra conciencia a través de los sentidos, si bien no pueden ser cuantificadas y catalogadas dentro de las leyes y teoremas establecidos por la

\footnotetext{
${ }^{21}$ QD 197-198.
} 
ciencia, sirven, sin embargo, de acicate en la búsqueda y dan jerarquía a otros valores, a aquellos del rango de la bondad, de la belleza o del amor, que brotan del fondo del hombre como luces y guías en su aventura de perfeccionamiento. Esto parece indicar que, dentro de la discontinuidad íntima, existen ciertas ordenaciones finales que dan al Universo su fisonomía estable o en desarrollo. Es indudable, entonces, que más allá del desconcierto que el estudio objetivo o matemático nos produce, existe una inteligencia ordenadora que hace que todo este aparentemente desordenado mundo fije bases que son las que dan realidad y permanencia al devenir universal.

Señala por lo mismo nuestro autor que los audaces avances actuales van dejando al desnudo la inconsistencia científica y filosófica del materialismo. La causalidad es de orden cualitativo; el determinismo es de orden cuantitativo. La primera implica solamente una sucesión temporal de los hechos, en cierto orden; el determinismo es más riguroso, pues puede predecir exactamente el fenómeno partiendo de la causa. La causalidad podría existir sin determinismo; este último es parte integrante de la causalidad. Así las leyes de la física y la química quedan reducidas a relaciones matemáticas que constituyen la “esencia" del fenómeno, el cual se "materializa" en la realidad observable. Y esta doble condición tiene la curiosa y trascendente significación de permitir a la investigación progresar, modificando o ampliando sus aplicaciones y su apariencia fenomenal. La causalidad señala solo una más o menos acentuada probabilidad, pero no una certeza absoluta, y por este camino caemos, finalmente, en las leyes naturales estadísticas, cuya precisión aumenta con el número de casos o elementos considerados. Ha aparecido aquí el carácter de probabilidad estadística de las leyes físicas que reglamentan fenómenos que son la integración de un considerable número de microfenómenos inciertos que, a la escala humana, se convierten en una verdadera certidumbre que crece con las observaciones. Es la escala la que le da la seguridad a la ley.

La ciencia no puede acercarse a la verdad última con una aproximación mayor que su discontinuidad que, para muchos hombres de ciencia, establece la capacidad límite de la inteligencia humana para descifrar el cosmos, para conocer el arcano de su discontinuidad que se muestra como una de las constantes universales. Ambas soluciones nos ponen, ineluctablemente, frente a la inteligencia, a la fuerza y al misterioso poder que Aldunate incorpora a su concepto de Dios y a través de cuyas ordenaciones la evolución 
del Universo material que conocemos inició su devenir. ${ }^{22}$

$\mathrm{Si}$ avanzamos hacia los dominios de la vida espiritual donde actúan los valores morales y se disciernen las nociones del bien y del mal, se separan los reflejos condicionados de la inteligencia abstracta y el hombre se hace capaz de manifestaciones "inútiles" como la belleza, la gracia y el ingenio; entonces el planteamiento materialista muestra su verdadera indigencia. El hombre puede actuar buscando su propio perfeccionamiento, aun cuando para ello deba dominar los instintos naturales del ser vivo en su condición exclusivamente somática. Si no tuviera libertad para ser más noble o más bueno; si no pudiera buscar con auténtica posibilidad de crearlas, fórmulas de belleza y de armonía, todo nuestro mundo sería locura y absurdo. Al infundirle a nuestra especie inteligencia y conciencia, al concedérsele un margen de autodeterminación que le permite influir, en cierta medida, en su proceso de superación, se le creó un acicate y una responsabilidad y se hizo posible la elección de una conducta y con ello la aparición de los conceptos del bien y del mal y de las normas morales. En la sabiduría de nuestro espíritu, la amplitud de la esfera que queda más allá de la reducida dimensión del ámbito que abarca la inteli-

\footnotetext{
${ }^{22}$ Aldunate QD 195, 201-205, 215.
}

gencia, al recibir a través antenas de nuestro ser solicitaciones que vienen de un mundo ajeno a la materia; al sentir el halo con que se nos hacen presente la bondad, la belleza, el amor y otras realidades que recibimos aún con más fuerza que la luz, el color o las ondas hertzianas, tenemos que aceptar que es en la desconocida ciencia de la vida y la inteligencia primero y en la quinta esencia de los fenómenos espirituales después, donde se albergan las verdades del mundo que nos rodea, la razón de ser de nuestro parpadear en la oscuridad y la esperanza de abrirnos a la inteligencia y del espíritu, a otro espacio que queda en el Universo de lo inmutable, de lo verdadero, de lo divino. Se ha hecho perentoria la necesidad de que la ciencia busque, con la ayuda de todos sus instrumentos, cómo hacer más suave y más plena nuestra corta estada sobre la Tierra, porque la bondad, el amor y la justicia están adquiriendo su debida jerarquía.

La ciencia habrá logrado su verdadero destino al procurar a la familia humana indicaciones certeras para las creaciones de la técnica y para las realizaciones materiales, y también, al inspirar al ser inteligente una filosofía que le permita hacer su jornada con la vista clavada en las alturas, penetrando las distancias insondables del Universo en busca de la Gran Verdad. Protegido por su íntima necesidad de 
creer en algo que esté más allá del Universo material que sus sentidos le entregan, y reconfortado por la certidumbre de una misión que cumplir en la obra de Dios y que ha de devolver al seno de su Creador, le será dado al hombre vivir al abrigo de su fe y del ambiente fraternal que haya sido capaz de crear a su alrededor.

Así, por el áspero camino de la ciencia vamos acercándonos a la verdad y es posible que algún día nos sea dado adivinar, más que descubrir objetivamente, muchas de las verdades que hoy se nos presentan como indescifrables misterios. $Y$ esto, aunque nos lleve en un lejano mañana a comprender lo que es la vida y aun a crearla. El hombre empezará entonces a justificar esa finalidad, esa teleología de la evolución. ${ }^{23}$ La frase del pórtico de uno de los libros de Aldunate dice: "El corazón del hombre encierra a Dios entero", porque allí dentro es donde ha nacido la conciencia de Dios; porque allí dentro sentimos esa fuerza que pugna hacia lo que no es simplemente material, ni siquiera simplemente animal; pugna hacia la luz, la sombra del Dios de Einstein que, como ya dije, en nuestra incapacidad expresiva encerramos dentro de los estrechos límites de la palabra espiritu.

Pero no son determinadas individualidades quienes han hecho posible el progreso. Ha sido la especie, en su teleológico andar, la creadora de las facultades y las tensiones intelectuales capaces de provocar y afirmar su marcha. Las coincidencias en descubrimientos en diversos puntos del globo son un poderoso argumento a favor de esta creencia. Tiene, por tanto, la certidumbre, vigorizada por los nuevos conocimientos: el Universo no es un caos y el devenir universal se atiene a leyes matemáticas y camina hacia un fin, aún desconocido, pero a juzgar por la experiencia y la intuición humanas, ubicado más alto en la escala del perfeccionamiento y de la complejidad del intelecto y del espíritu. ${ }^{24} \mathrm{~A}$ pesar de la apatía de "casi cada hombre", la familia humana camina en busca de algo, impulsada por su desconocido destino. Hay una curiosidad colectiva, casi inconsciente, deseosa de saciarse; y algunos seres elegidos, muchas veces sin apercibirse de ello, buscan, imaginan, crean... y resuelven; y muestran caminos para realizaciones portentosas no previstas en sus intentos originales. Son los instrumentos de la desconocida finalidad de la vida, destinados a producir el avance; son los encargados de orientar las instintivas tensiones teleológicas ejercidas a través de largos periodos del viaje de la especie hacia su

${ }^{23}$ QD 262, 254.

${ }^{24} \mathrm{CA}$ 62, 136. 
ignoto, pero ciertamente, encumbrado destino.

La mencionada definición expresa que la ciencia es una tentativa para lograr que los conocimientos adquiridos por medio de las informaciones recibidas por nuestros sentidos correspondan a un sistema de pensamiento lógicamente ordenado; es decir, se buscan los ritmos, los sistemas, las relaciones, con los cuales los fenómenos se realizan; se buscan los cómo o de qué modo se llevan a cabo, pero nunca el intrínseco porqué de ellos. La lógica más elemental exige no solo una razón de ser de los fenómenos, sino fundamentalmente la existencia de un ser, un ente o algo con la sabiduría e inteligencia capaces de crear todas las leyes, matemáticamente estructuradas e interconectadas entre sí de algo tan complejo y tan vasto para nosotros los hombres en el tiempo y el espacio, como el cosmos universal. La huella digital matemática del Creador, usando un lenguaje muy humano, aparece en la descripción de todos los fenómenos universales. ${ }^{25}$ De todo este esfuerzo de crítica y autoanálisis ha ido emergiendo una imagen más verdadera de la realidad universal, aunque todavía eminentemente subjetiva, resultado de la interpretación realizada por nuestro sistema cognoscitivo y neurológico de noticias incompletas o deformadas.

$$
{ }^{25} \text { LD } 125 .
$$

La ciencia avanza a pasos acelerados; el conocimiento se profundiza pero, a medida que la inteligencia penetra en los nuevos campos, se hace más amplio su contacto con lo desconocido. Los feudos de la física llegan hasta ciertos límites; más allá aparece el mundo al cual solo el pensamiento alcanza y es, por ende, imposible de ser medido u objetivado. En el artícu10 “¿Ha muerto Dios?”, recopilado en Hombres, máquinas y estrellas, Aldunate explicita los que a su juicio son los dos ejemplos más patentes de la realidad metafísica: la explicación del ego individual y de la organización matemática del Universo.

El cosmos no deviene como un conjunto sin sentido. No es un caos marchando a la deriva, sino que obedece a reglas que estamos empezando a formular con nuestra limitada aptitud para conocer material e intelectualmente la realidad de la que formamos parte. El comportamiento del mundo físico y aun del mundo espiritual es evidentemente evolutivo, entendiendo por evolución un progreso en la morfología y en la calidad de los seres, una búsqueda tras un fin, una tendencia teleológica hacia formas cada vez más complejas y perfectas. La evolución y sus mutaciones constituyen la suprema forma de progreso. ${ }^{26} \mathrm{El}$ hombre

${ }^{26}$ Por otra parte — señala-, la posible aparición en el futuro de altas inteligencias o la existencia actual de seres de otros mundos neurológicamente 
ha intuido la existencia de una sabiduría y de un poder, de una inteligencia ajena a su comprensión. En su afán por pensar e imaginar, confirió a ese poder creador y organizador apariencias antropomórficas con las limitaciones y las deformaciones propias de su ignorancia. Por ello la respuesta a la muerte de Dios debe ser clara, previa una contra pregunta: ¿A qué Dios se refiere? Si es al Dios del castigo del infierno y la venganza, del temor y la mano amenazante, es indudable que esa caricatura de Dios ha muerto. Pero, en cambio, se ha revelado más puro, más realmente omnipotente, el Dios de la sabiduría, de la belleza, de la bondad y del amor. ${ }^{27}$ El Dios de los hombres de hoy ha adquirido una más alta jerarquía y se ha ubicado más lejos de su mano, más inaccesible al conocimiento, pero más pertinente a la zona ignota en la cual se le sitúa.

El creador de un Universo con flores y estrellas y con hombres, frutos del amor, sin olvidar la justicia, la esperanza y todos aquellos dones capaces de quitar a la vida la beligerante aspereza con que hoy nos lastima; el que incrustó en la profun-

más desarrollados o con un conocimiento más cabal de la creación no invalida la idea de Dios, sino todo lo contrario. Como dijo el genial jesuita Teilhard de Chardin, "la epopeya grandiosa de la evolución universal se revela como el regreso de todo a su Creador'. Cfr. HE 132-133.

${ }^{27} \mathrm{HE} 135$. da entraña de la materia primigenia la tendencia al perfeccionamiento y el itinerario que lleva hacia etapas más altas donde prevalecerá el espíritu: en fin, el Dios del amor, es el que llevan todos los hombres, muchas veces sin saberlo, en el fondo de sus corazones. Allá adentro en la ignota profundidad del sí mismo, presiente y anhela una finalidad universal, una teleología de la cual no puede evadirse y que lo obliga a creer y a esperar. Utilizando nuestra lógica elemental, resulta indispensable, entonces, dentro de nuestro concepto de Universo, la existencia de un poder, de un algo ordenador capaz de programar, dirigir y dar un sentido a este acaecer, a primera vista anárquico y desordenado pero que muestra los ritmos, las tácticas o los sistemas rigurosamente matemáticos a los cuales sujeta su conducta. $^{28}$

\section{Presencia de Dios ${ }^{29}$}

Todos los descubrimientos y postulados se atienen a leyes, ritmos, combinaciones numéricas o interrelaciones rigurosamente matemáticas. Esto señala que el cosmos teje su devenir

${ }^{28} \mathrm{HE} 136,139,130$.

${ }^{29}$ Aldunate sigue la líneas de Santo Tomás con sus cinco caminos para acercase a Dios, asumiendo de manera especial el último, al señalar que el orden de la realidad postula la existencia de un ordenador. 
en una malla, en una urdimbre en la que los números tienen un papel definitivo. En el momento de la Creación debieron ser también creadas las ecuaciones y algoritmos que regirían el permanente acontecer del orbe. Utilizando los razonamientos más estrictos y la lógica más ajustada, llega al coincidente aserto de que la confirmación experimentada y filosófica de mayor trascendencia para el hombre establecida por la ciencia de hoy, es la rigurosa e interrelacionada ordenación del Universo. El acaecer cósmico demuestra poseer un sentido teleológico, que el hombre intuye más alto, más espiritual y digno de un Supremo Creador, propia de Dios.

Por lo mencionado, los ejemplos de tan singular ordenación y de tan incomprensibles realidades deberían ser propuestos y descritos con claridad, perfección y belleza. Así ayudarán a construir la silueta del hombre en su carrera de evolución, no solo intelectual, sino también espiritual y moral, a pesar de que para ello se utilicen elementos puramente materiales, cuyas proyecciones en el campo filosófico han sido olvidadas o despreciadas. Estos elementos permiten reconocer el parentesco del ser inteligente, espiritual y moral, con el Supremo Hacedor y justificar su condición, su abolengo "de Hijo de Dios". ${ }^{30}$

${ }^{30}$ LD 111, 127; QD 235
Dios, sin perder su encumbrada jerarquía, es la inteligencia ordenadora, el principio y el fin, la ley fundamental y la génesis del cosmos. ¡Más allá del principio, más allá de la física, en la metafísica! La ley, el sistema, la razón de ser, la sabiduría, el poder, es lo que los hombres, dándole diversas características, han llamado Dios. Respuesta a lo desconocido, creador de quien no conocemos sus condiciones y en cuya Creación encontramos su huella. Este reconocimiento de un poder, de una inteligencia ordenadora superior, como decía Einstein, no es una posición dogmática; es una necesidad conceptual, cada día más ávida, un requerimiento del intelecto más exigente. ${ }^{31}$ La ordenación lógica mencionada por Einstein aparece cada vez más claramente.

Naturaleza, el Universo, la Materia y la Energía es evidente que no constituyen un caos ni se comportan anárquicamente. Su sistematización se muestra por todas partes cada día con más evidencia. Todas las informaciones con que se hace presente la Creación están matizadas matemáticamente. El color verde tiene como definición última, números: largo de onda, velocidad; las ondas de radio, el calor, los rayos $\mathrm{X}$, números rigurosamente coordinados; las

\footnotetext{
${ }^{31}$ HL 29, 274
} 
órbitas de los planetas, de las galaxias y de todos los mundos estelares, obedecen a ecuaciones y relaciones numéricas; las macropartículas, protones, electrones y demás se ordenan y atienen a un sistema que, mientras más vasto, paradojalmente, aparece menos caótico. Todo esto les está devolviendo, a quienes caminan en las avanzadas del progreso y divisan desde mayor altura el panorama universal, su capacidad de asombro ante el misterio y una modestia para aceptar, sin sentirse por ello disminuidos, la existencia de una razón de ser, aun incomprendida, de este prodigioso proceso, en cambio permanente y sistemático, que se advierte por doquier.

El ansia de conocer, de perfección, de progreso, no se aquieta; los hombres empiezan a sentirse parte de este grandioso plan universal en el cual, además de la materia y la energía y sus leyes, existen otras realidades. Sus espíritus perciben acontecimientos orlados de belleza, de amor y justicia, perfeccionados o complicados con características reales pero de una índole inalcanzable para la ciencia, imposible de ser cuantificada u objetivada: una jerarquía de orden ético y espiritual. Los ejemplos demostrativos de la matemática del Universo, imposible de ser atribuida a la generación espontánea o al azar, no pueden alejar a aquellos que se motivan por las ciencias exactas... Por esta senda el hombre encontrará la libertad del espíritu y las fuentes del amor y el saber capaces de entregarle la verdadera felicidad. El hombre recibió como dones de Dios una cualidad: conocer, conocerse y que saber que conoce... y además la ley del amor. Entre sus atributos tenía también el de decidir sobre el empleo que daría a los conocimientos adquiridos y a su capacidad para amar.

Pero las palabras y el lenguaje constituyen los elementos estructurales básicos de nuestras formas de expresión y comunicación. Son los que nos permiten pensar. El hombre, ser racional, no tiene posibilidad alguna de raciocinar, imaginar o crear sin la intervención de las palabras. "Primero fue el Verbo", dice San Juan. En esta epopeya teleológica del Creador, ¿no se advierte la existencia de la huella digital surgiendo ordenadora dentro de un programa cuya finalidad desconocemos? La tarea de conservar y regir el Universo resulta ser un concepto humano, y la dimensión temporal una mera limitación del modo de conocer del hombre. Es por estas complejas características de la Creación, y por ende de su Creador, que no podemos ni definirlo apropiadamente, ni imaginarlo. ${ }^{32}$ Religión es creencia en un Ser Supremo, en

${ }^{32}$ LD 22, 34, 39, 49, 81. 
un Creador omnisciente, en Dios. Arquetipo religioso es la actitud innata en el hombre que, nacida en su ego inconsciente, lo lleva a "sentir" y después a aceptar ese algo impenetrable del cual surgen como sus manifestaciones elementales la belleza, las razones profundas y la integral sabiduría. El arquetipo religioso es connatural al hombre, ${ }^{33}$ como su capacidad de atisbar la inconfundible "huella digital matemática" de Dios.

Si se analiza con cuidado el camino seguido por descubrimientos e investigaciones del mundo de las ciencias, podrá advertirse que han sido posibles gracias a que en los fenómenos observados tanto en el macrocosmos circundante como en las más profundas lejanías cósmicas las ordenaciones, ritmos, relaciones y sus modos de hacerse presente mantienen la rigurosa huella digital matemática, inconfundible, de la mente y la mano sabia de Dios Creador. Y se agrega otra idea, como un permanente leitmotiv de su obra: los números y la ordenación matemática expresada en los algoritmos referentes al mundo físico y al biológico no fueron inventados por los hombres; estos solo han ido descubriéndolos: nacieron con la Creación universal. La Suprema Inteligencia de Dios, creadora de la urdim-

${ }^{33}$ También el ateísmo proporciona un nuevo y poderoso argumento para mostrar la invencible tendencia religiosa natural del hombre (LD 132). bre matemática sobre la cual se teje el devenir cósmico, ha dispuesto que los movimientos de todos los objetos materiales del Universo no fueran indiferentes para sus dimensiones témporo-espaciales. A escala infinita fructifica la semilla energética del árbol cósmico, y se expanden y cumplen los ciclos establecidos por Dios. La luz, energía alboral del Universo, sería el fruto de la semilla intangible, arrojada por $\mathrm{Su}$ mano sabia en los ámbitos inexistentes de la nada.

Desde el vocablo luz cabe admirar la extraordinaria capacidad expresiva y poética del genio de la relatividad al llamar a este ente físico, que no solo ilumina, sino que además constituye la materia prima del Universo, la sombra de Dios. La luz es semilla de estrellas, eterna viajera a la velocidad única y constante, bellota del árbol cósmico, trazo de las distancias en la curvatura interminable del espacio y sombra de Dios, el Supremo Creador. ${ }^{34}$

Por otra parte, resulta lógico que el Creador del Universo existiera en un eterno presente y una realidad sin dimensiones. Para Dios no puede ser nada pasado, no puede estar nada por suceder. Pero la dificultad estriba en la necesidad de olvidar, al hacer estas elucubraciones, nuestra permanente tendencia al antropocentrismo y el descartar que el presente no existe para

${ }^{34}$ LD 185, 203, 226, 230. 
el hombre: sus acciones, sus pensamientos y aun sus palabras son siempre futuro mientras no se realizan y se convierten bruscamente en pasado tan pronto como se actualizan o se construyen. Esta condición no puede pertenecer a Dios. El hombre, hijo de Dios, disfrutaría, pero solo como un destello de inteligencia, la capacidad de imaginar, de pensar, y de aquí la tentativa científica para lograr que esa desordenada práctica corresponda a un sistema de pensamiento lógicamente ordenado. La huella matemática de Dios, que la ciencia descubre cada día en forma más clara en la estructura y el devenir cósmico exige, requiere, un Omnisciente Creador cuya huella "digital" matemática inconfundible aparece como secreto nexo entre cada nuevo resultado de la ciencia.

Desde lo más profundo de nuestro ego surge una respuesta como una verdad intuitiva expresada sin asomo de duda: el todo universal, la realidad absoluta es eterna, imperecedera como su Creador. ${ }^{35}$ La noción de Dios y la actitud religiosa derivada de ella no se contraponen ya como antítesis de la ciencia, como era costumbre hacerlo. Las matemáticas llegan ahora, conscientemente, hasta los lindes de la metafísica, en cuyo campo se levanta la idea del Ser Supremo. Hoy se aprecia hasta dónde alcanzan las ciencias y se reconoce la existencia y la vastedad de ese otro mundo situado fuera de su dominio. De tal modo - reitera Aldunate-, en el mundo de hoy, en el que tantos hombres y naciones se han olvidado de Dios y de su ley del amor, cuyo cumplimiento es el que diferencia al ser inteligente de los seres irracionales, en estos días de crisis moral en que la paz, la justicia, la bondad, la lealtad, la generosidad y otras condiciones, hijas del amor, han sido olvidadas y pisoteadas, un resurgimiento espiritual, una vuelta a Dios empieza a despertar entre los hombres. Son anhelos y sueños que nada ni nadie logrará destruir, porque su realización es parte del destino fijado por quien todo lo crea y dispone. 